\title{
BEHAVIOURAL, BIOCHEMICAL AND NEUROCYTOARCHITECHURAL IMPACT OF MDMA IN MALE ADOLESCENT MICE
}

\author{
Oloruntola B.J, Adeniyi P.A, Ishola A.O, Ogedengbe O.O, Olatunji B.P, Olabiyi A.A, Shallie P.D
}

Correspondence to: *Adeniyi P.A, . Cell Biology and Neurotoxicity Unit, Department of Anatomy, College of Medicine and Health Sciences, Afe Babalola University, Ado-Ekiti, Ekiti State, Nigeria ade.adeniyi@abuad.edu.ng; +2348032922323.

\begin{abstract}
Neurotoxicity of 3, 4-Methylenedioxymethamphetamine (MDMA, ecstasy) is still controversially discussed. MDMA is an amphetamine derivative that has gained significant popularity in recent years and has become the recreational drug of choice for many young, adolescents and adults. This study sought to investigate that MDMA causes a behavioral, biochemical and neurocytoarchitechural change in male adolescent mice. Fifteen adolescent male mice were used for this study. They were randomly divided into 3 groups, of five mice each, control group received normal saline (Ctrl), 5 mice received $10 \mathrm{mg} / \mathrm{kg}$ of MDMA, S.C (LoD) and another 5 mice received $20 \mathrm{mg} / \mathrm{kg}$ of MDMA, s.c (HiD). The animals were subjected to behavioural tests to check their motor activity. Biochemical analysis to test for the level of catalase and monoamine oxidase activity was also done. The motor activity of animals treated with 10 $\mathrm{mg} / \mathrm{kg}$ and $20 \mathrm{mg} / \mathrm{kg}$ of MDMA was significantly $(\mathrm{p}<0.05$ ) lower when compared with the control. Likewise, there was a reduction in the catalase and monoamine oxidase activity in the treated groups. In the cerebellum, cellular distortion was seen in the treated group. It could be concluded that MDMA affects the motor activity of the treated animals and thus cause an alteration in the neurocytoarchitechure, catalase and monoamine oxidase activities of the animals.
\end{abstract}

Keywords: MDMA, Motor function, Hippocampus, Cerebellum, Biochemical.

\section{INTRODUCTION}

Neurotoxicity of 3, 4Methylenedioxymethamphetamine (MDMA, ecstasy) is still controversially discussed. MDMA is an amphetamine derivative that has gained significant popularity in recent years and has become the recreational drug of choice for many young, adolescents and adults (Bankson and Cunningham, 2001). Like amphetamine, MDMA elicits hyperactivity when administered to rodents. Unlike amphetamine, which has effects mediated by the release of dopamine (DA) from nerve terminals, MDMA-induced hyperactivity is thought to be dependent upon the release of 5hydroxtryptamine (5-HT, serotonin) (Bankson and Cunningham, 2001). The positively rated effects of MDMA consumption include euphoria, arousal, enhanced mood, and increased sociability, a general sense of well-being, decreased anxiety and heightened perceptions as a hallmark of the MDMA experience (Morgan, 2000; Parott, 2001). Some common adverse reactions are nausea, headache, tachycardia, bruxism, and trismus (Meyer, 2013). Lowering of mood is an aftereffect that is sometimes

Submitted $16^{\text {th }}$ June 2016 , revised on $12^{\text {th }}$ January 2017. Published online $20^{\text {th }}$ January 2017. To cite: Oloruntola B.J, Adeniyi P.A, Ishola A.O, Ogedengbe O.O, Olatunji B.P, Olabiyi A.A, Shallie P.D. 2017. Behavioural, biochemical and neurocytoarchitechural impact of MDMA in male adolescent mice. Anatomy Journal of Africa. 6: 884 - 895. 
reported from 2 to 5 days after a session of ecstasy use (Meyer, 2013).

The United Nations estimated that global ecstasy use affects some nine million people of the population between 15 and 64 years. There are more than three million ecstasy users in Europe accounting for $36 \%$ of ecstasy users worldwide. The annual prevalence rate of 'ecstasy' use is estimated at $0.9 \%$ of the population age $15-64$ in the west and central Europe, exceeding the level reported from North America (0.8\%) (UNODC, 2007).
In the European Union (EU), the European monitoring center on drugs and drugs addiction estimated that more than one million adults take ecstasy every month. In the United Kingdom (UK) alone, it is estimated that every weekend, 500,000 young people consume the drug (EMCDDA, 2007). Traditionally, population surveys have shown that after cannabis, amphetamines are the most commonly used illegal substances (Johnston et al., 2008). The aim of this work is to access the behavioral, biochemical and neurocytoarchitechural changes in the hippocampus and cerebellum of adolescent mice after the induction of MDMA.

\section{MATERIALS AND METHODS}

\section{Experimental animals}

Fifteen (15) adolescent male mice were used for this study. The animals were obtained from the animal holding facility of Afe Babalola University, Ado-Ekiti, Nigeria. The animals were allowed to acclimatize for 5 days and had free access to standard pellet (purchased from the ABUAD feed mill, Ado-Ekiti) and clean water.

\section{Experimental design}

The mice were randomly divided into 3 groups, of 5 mice each in a standard laboratory environment with controls humidity, pressure, and temperature. The treatment protocol was in accordance with the ethical requirement of the Animal Use and Care Committee of Afe Babalola University, Ado-Ekiti, Nigeria. Control group received normal saline (Ctrl), low dose received $10 \mathrm{mg} / \mathrm{kg}$, s.C MDMA (LoD) and high dose received $20 \mathrm{mg} / \mathrm{kg}$, s.c MDMA (HiD). The mice were treated for 21 days.

\section{Drug}

The drug was requested by P.A. Adeniyi from the National Drug Law Enforcement Agency (NDLEA) head office for the research. The drug was delivered to him with a letter with ref no. NDLEA/DP/3/VOL.1. The total of $14.64 \mathrm{mg}$ of MDMA was used for the study.

\section{Behavioral analysis}

The behavioral tests were carried out in a closed area with proper illumination and sound control behavioral room of Afe Babalola University holding.

All behavioral test performance was captured using a digital video recorder and were later analyzed. The following tests were carried out;

- Rotarod test: rotarod test were done to assay for motor coordination (Deacon, 2013). The animals were placed on a rotarod as described by Perrine and Takesue (1968) to determine the latency of fall (LOF) and passive rotation (PR). The maximum duration allowed was 5 minutes.

- Open field test (OFT): This was done to test for the locomotive activities of the mice. OFT was made of white wood with dimensions, $100 \mathrm{~cm}$ wide, $100 \mathrm{~cm}$ long, and $50 \mathrm{~cm}$ high and was marked with dark lines dividing the floor into 16 uniform square and a center square. A high definition video recording system (SONY) was placed in a position to capture all corners and sides of the open field area (OFA) in order to record animal movement and behavior (Ajonijebu et al., 2014). For the actual test, the animals were allowed to freely move about for 5 minutes following which analysis was done for the total locomotive activity of 
the mice using the following equation (Adeniyi and Olatunji, 2015).

Total locomotive activity (TLA) $=$ sum of line crossed + number of rearing

\section{Animal sacrifice}

After administration, two (2) mice from each group were sacrificed by cervical dislocation on day 21 of the treatment and their brains were perfused with $10 \%$ formalsaline and transferred quickly to a specimen bottle containing $10 \%$ formalsaline (Baron, 1986; Adeniyi, 2010). Thereafter, the hippocampus at bregma $1.82 \mathrm{~mm}$ using stereotaxic atlas (Franklin and Paxinos, 2007) and cerebellum was excised to process for histological analysis. Also, the other three (3) mice from each group were sacrificed by cervical dislocation and their brain were harvested and transferred into $30 \%$ sucrose in a frozen environment in order to preserve the chemicals for biochemical analysis.

\section{Histological analysis}

After the tissue samples were fixed $10 \%$ formalsaline, they were dehydrated, embedded in paraffin wax and sectioned with a rotary microtome at $5 \mu \mathrm{m}$. They were then stained in cresyl echt violet stain and PTAH (phosphotungstic acid hematoxylin) stain to demonstrate for the glial fibers, nissil substance in neurons and of astrocyte respectively.

Routine H\&E (hematoxylin and eosin) stain were also been used to give a general overview of the tissues.

\section{Biochemical analysis}

The biochemical assay was done to ascertain the catalase activity in the tissue samples as well as the monoamine oxidase (MAO) activity.

\section{Statistical analysis}

The data used were generated from the recorded videos manually. A number of the perpendicular lines crossed was used to determine the locomotive activity. The data was plotted in one-way ANOVA (GraphPad Prism Version 6.0) with Tukey posthoc test. Significance was set at $* P<0.05$ and results were expressed as means \pm standard error of the mean (SEM).

\section{RESULTS}

\section{Gross morphological observations}

There were no changes in the skin color and the color of their eyes was normal compared to the control groups throughout the administration period. During the course of administration, it was observed that $\mathrm{HiD}$ animals were relatively more alert to their environment and showed restless when compared with the control and LoD animals. Similarly, comparing the LoD animals showed more agility and sensitivity than the control. After the $1^{\text {st }}$ week of administration, an increase in body weight was observed in all groups throughout the experiment but no significant difference $(p>0.05)$ in weight change was observed throughout (see fig. 1).

\section{Motor Activity}

Rotarod test: a significant decrease in LOF was observed in LoD animals $(P<0.05)$ when compared with the control. Also, decrease in LOF was observed in HiD animals when compared with control. HiD animals showed greater LOF when compared with LoD animals but no significant difference ( $p>0.05)$ was observed.

Open field test (OFT): LoD animals show significantly low locomotor activity compared to HiD animals and control group $(p<0.05)$. No significant difference was observed between the control group and HiD animals ( $P>0.05)$. 


\section{Biochemical parameters}

\section{Catalase}

LoD animals show significant reduction of catalase activity compared to the control $(p<0.01)$. No significant difference was observed between control and HiD animals. High dose treated animals had high catalase activity than the low dose treated group but no significant difference between the two groups.

Monoamine oxidase (MAO) activity:

Monoamine oxidase activity of LoD animals is significantly lower than the control group $(P<0.01)$. HiD animals show low MAO activity than the control group and higher activity than LoD animals but no significant difference was observed ( $P>0.05)$.

\section{Histological observations}

\section{Hippocampus:}

The LoD possess more granular cells than the control group in terms of density, although relatively they are similar. HiD is not densely packed due to its invasion into the molecular layer. The granular cells are not in clustering orientation. The cells in HiD are quite scattered and display lesser denseness in orientation when compared with LoD which is relatively more packed. In LoD and the control group, their fibers were not so picked by the stain, but the LoD seems to appear more densely packed with more glial cells in a dense orientation than the control group. Comparing the control group and the HiD, the difference in both groups is quite significant with HiD appearing more densely packed than the control group. In comparing the treated groups, the LoD appearing similar to the control group making it relatively less dense than the HiD in terms of glial fibers and glial cells.

\section{Cerebellum:}

Comparing the control group and low dose treated group (LoD), the cells in LoD appears more densely packed than the control group and are also the cells are more deeply stained. Also in the high dose treated group (HiD), the cells appeared freely packed, but their cytoarchitecture appears similar to the control group. The Purkinje cells in LoD and HiD are majorly distorted with LoD cells shape appeared like it going through necrosis. Unlike the treated groups, the control group is normally shaped (oval) with slight vacuolation. LoD group appears to have lesser stained neuronal cells when compared with the control group. In terms of density and sparseness of neuronal cell, the control group appeared to be denser than HiD. Overall, both LoD and HiD show similarities in terms of cellular density and arrangement in the tissue. Comparing the control and the treated groups, the shape of the Purkinje cells in the control group are oval with no sign of distortion but in the LoD and HiD major distortion of the cell shape from an oval shape to spherical shape was been observed as well as vacuolation. Comparing the HiD and LoD, HiD appeared to be more prominently distorted. LoD treated group appeared to possess more cells than the control group but the glial fibers are not easily identified but in the control group, the fibers are clearly visible. Like the LoD, HiD to have almost no signs of glial fibers but still dominate in the density of glial cells when compared with the control group. LoD possesses more glial cells than HiD in terms of density. Observing at X100, the control group has more visible glial cells and fibers when compared with the treated groups due to lesser density in the glial cells and fibers. Comparing $\mathrm{HiD}$ and LoD, HiD appears to have more densely packed glial cells and fibers making it not quite visible. 


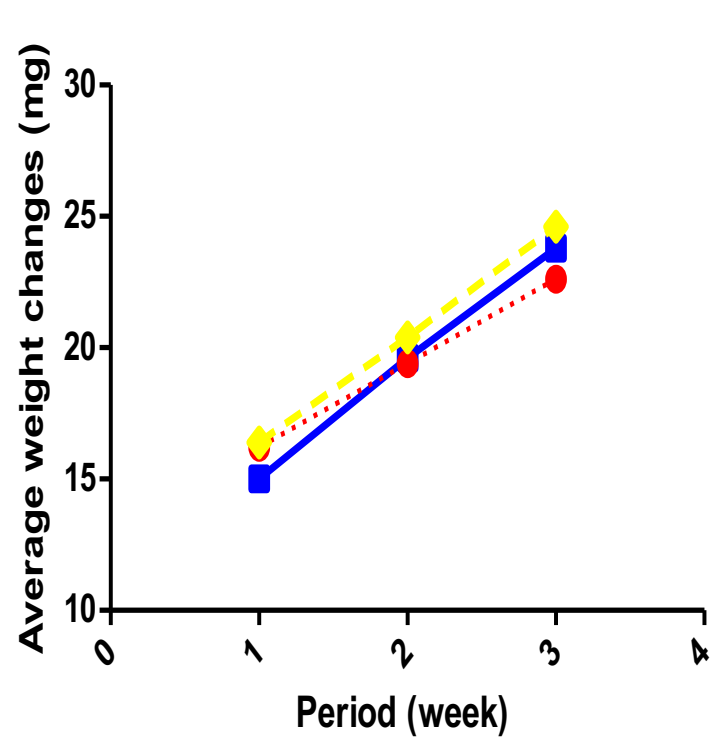

KEY:

Ctrl: control group

- HiD: high dose $(20 \mathrm{mg} / \mathrm{kg})$ of MDMA

LoD: low dose $(10 \mathrm{mg} / \mathrm{kg})$ of MDMA

Figure 1: Line graph showing average body weight change of the experimental animals for 3 weeks. There is no significant difference $(P>0.05)$ in the weight change of the animals throughout the 3 weeks of administration.
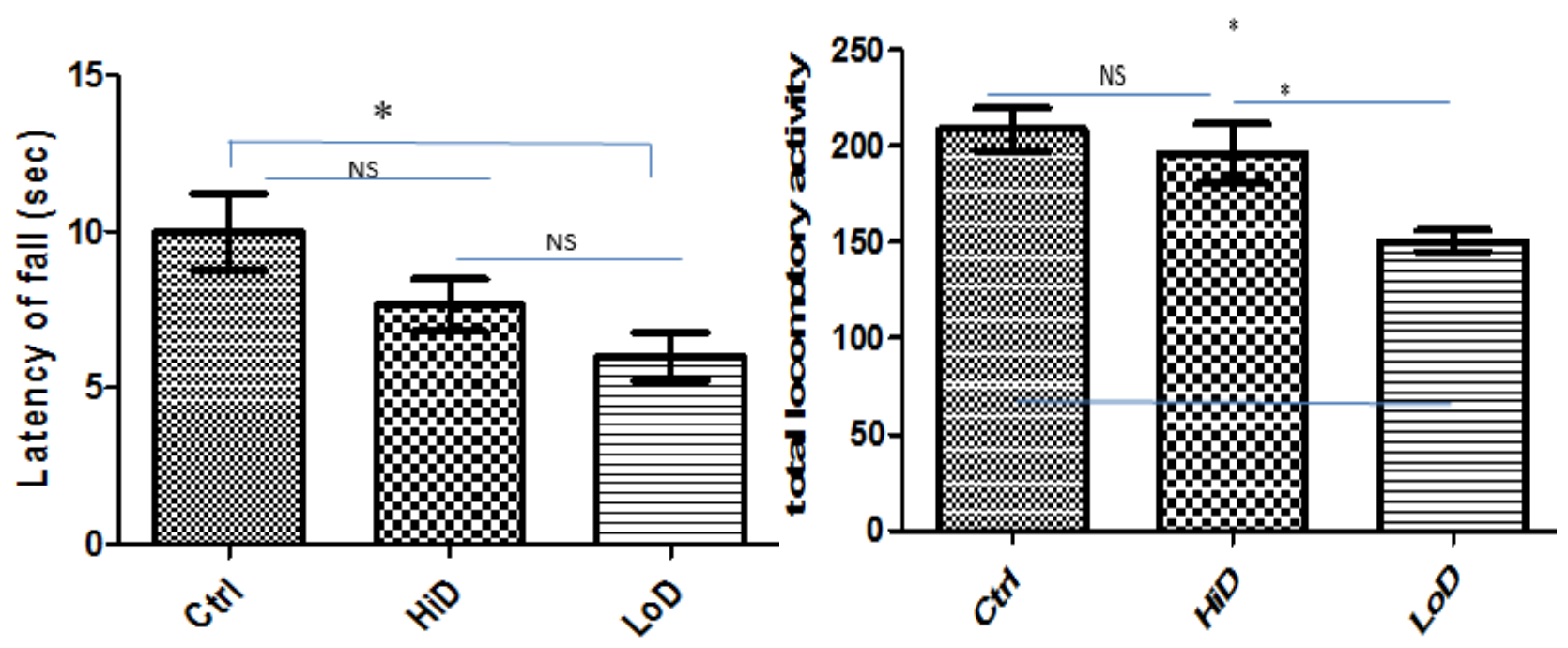

Figure 2: Graph showing the motor activity of the experimental animals. Latency of fall (LOF) of animals treated with $10 \mathrm{mg} / \mathrm{kg}$ of MDMA is significantly lower than the control group $(* p<0.05)$ (left image). The locomotor activity of the experimental animals are shown in the right image. Animals with $10 \mathrm{mg} / \mathrm{kg}$ of MDMA is significantly lower than the high dose treated animals and the control group $(* p<0.05)$. 

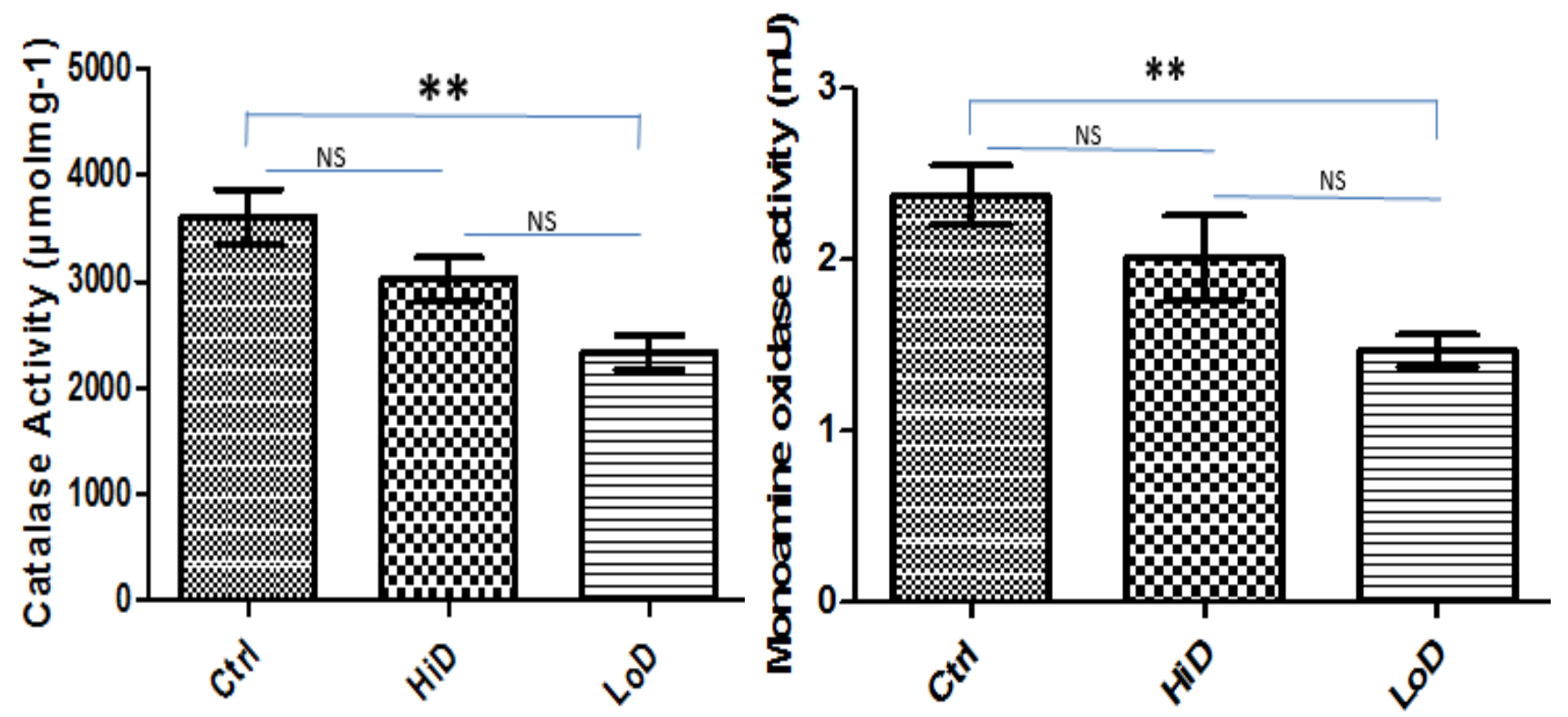

Figure 3: Graph showing the biochemical assays (catalase $(\mathrm{L})$ and monoamine oxidase (R) activity) of experimental animals. Animals treated with $10 \mathrm{mg} / \mathrm{kg}$ of MDMA is significantly lower than the control group $(* * p<0.01)$. Monoamine oxidase (MAO) activity of animals treated with $10 \mathrm{mg}$ of MDMA is significantly lower than the control group $(* * p<0.01)$.
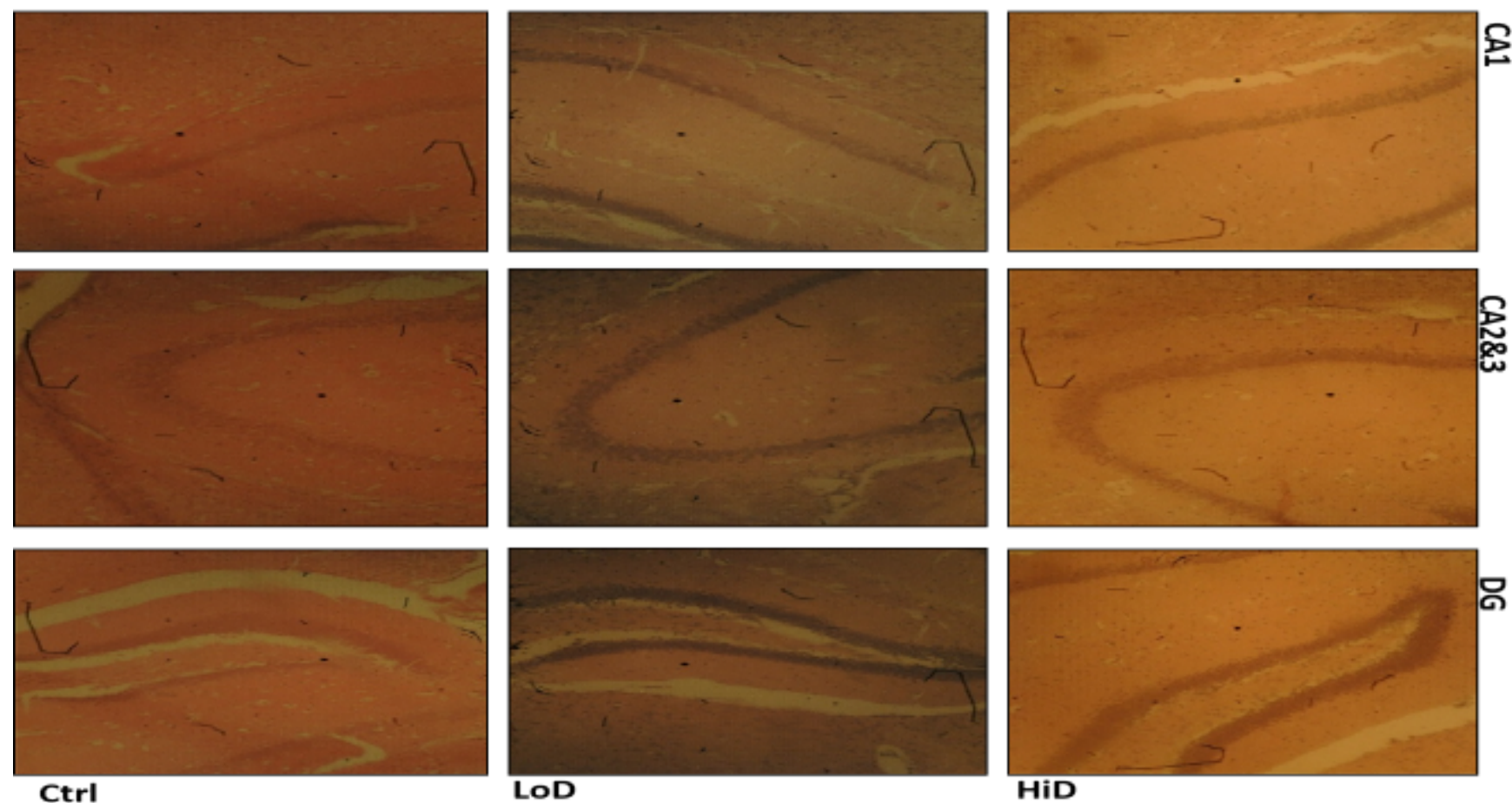

Figure 4: Histological slides showing the CA1, 2 and 3 and Dentate gyrus (DG) region of the hippocampus (X10, H\&E). GL (granular layer), ML (molecular layer) 

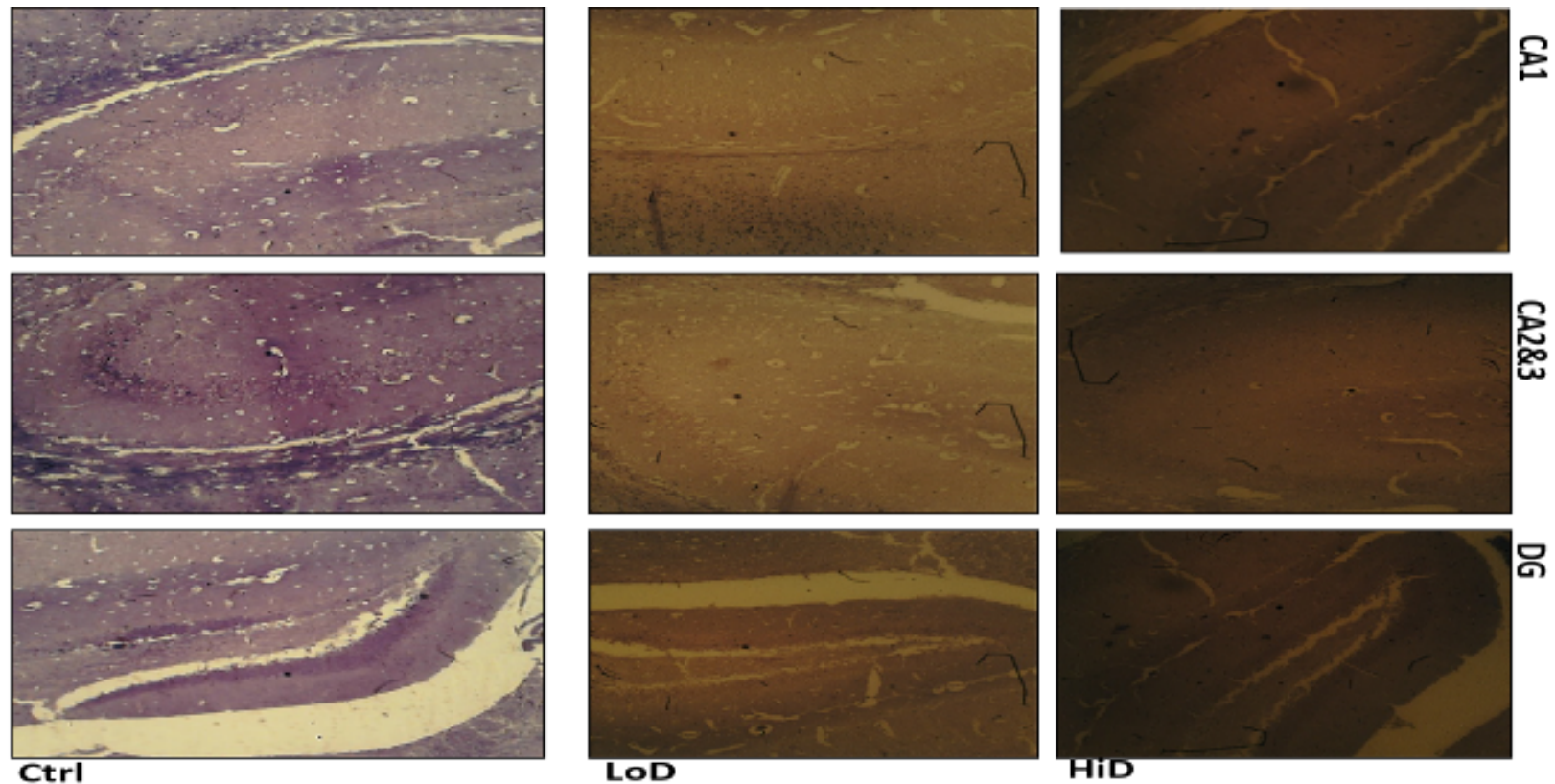

Figure 5: Histological slides showing the CA1, 2 and 3 and Dentate gyrus (DG) region of the hippocampus (X10, PTAH). GL (granular layer), ML (molecular layer)
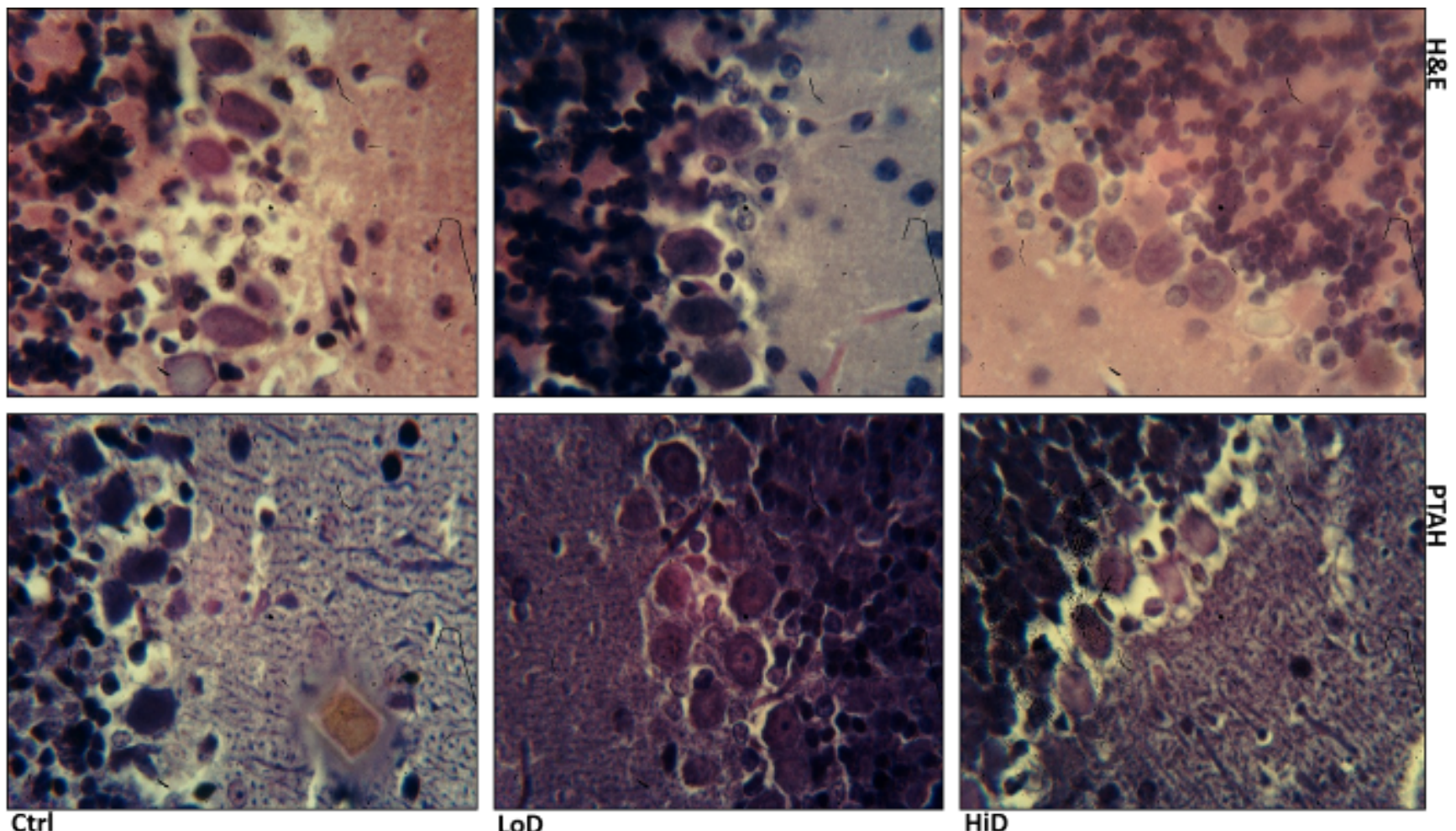

Figure 6: Histological slides showing the granular layer, Purkinje cell layer and molecular layer of the cerebellum (X100, H\&E and PTAH). 
Anatomy Journal of Africa. 2017. Vol 6 (1): 884 -895

\section{DISCUSSION}

\section{Gross morphology and general observations}

In the present study, no morphological changes were observed (skin and eyes color) in the treated animals when compared with the control. Addict or drug dependent people usually don't exhibit changes in the skin color as well as eyes color in the short term. Although there were changes in the average body weight, but there is no significance difference between the treated groups when compared with control group at $95 \%$ confidence interval $(p>0.05)$ (see figure 1 ). During the period of administration, some behavioural changes were observed in the animals treated with different doses of MDMA (10 mg/kg and $20 \mathrm{mg} / \mathrm{kg}$ s.c) when compared with those in the control group; the treated animals were relatively more alert to their environment (an indication of an increase in anxiety level) and showed restlessness when compared with the control group.

\section{Monoamine oxidase (MAO) activity}

MAO is a family

of enzymes that catalyze the oxidation of mono amines (Tiptpn et al., 2004; Edmondson et al., 2004). They are found bound to the outer membrane of mitochondria in most cell types in the body. MAO helps in catalyzing the breakdown of dopamine to dihydroxy phenylacetic acid (DHPA) which is a direct precursor of dopamine. Biochemical analysis of the experiment animals in this study showed a significance reduction in the monoamine oxidase (MAO) activities (see figure 5) when compared with the control $(P<0.01)$; this result agreed with findings of Efihirnia et al, (1994) MDMA had been reported to act has MAO activity inhibitor by preventing the conversion of dopamine in the synaptic cleft into DHPA (Efthimia et al., 1994). A significant reduction in MAO activity will result in a reduction in DHPA leading to high level of dopamine in the system. The accumulation/retention of dopamine in the system will result in hyperexcitation and if this continues for a longer period would result in excitotoxicity, glial cell activation (indicated by the prominent glial fibers), gliosis and neuronal death (See figure 15).

\section{Catalase activity}

Free radicals are atoms or groups of atoms with an odd (unpaired) number of electrons and can be formed when oxygen interacts with certain molecules (Orchin et al., 2005). Once formed these highly reactive radicals can start a chain of reaction. These free radicals are very reactive and they can react with most of the micromolecules in the system even with those that normally doesn't react in their natural state such as DNA. Their chief danger comes from the damage they can do when they react with important cellular components such as DNA, or the cell membrane; this in cells dysfunction and eventually can result in cell death (Conte et al., 1996). To prevent free radical damage the body has a defense system of antioxidants, free radicals scavengers, e.g. catalase. Catalases are antioxidants that catalyze the conversion of hydrogen peroxide to water and oxygen, using either an iron or manganese cofactor (Zámocký and Koller, 1999; Chelikani et al., 2004). This protein is localized to peroxisomes in most eukaryotic cells (del Rîo et al., 1992). Catalase is an unusual enzyme since, although hydrogen peroxide is its only substrate, it follows a ping-pong mechanism. Here, its cofactor is oxidized by one molecule of hydrogen peroxide and then regenerated by transferring the bound oxygen to the second molecule of the substrate (Hiner et al., 2002). The result from this study reveal that MDMA significantly decreases $(P<0.01)$ the level of catalase activity in the brain of the MDMA-treated groups when compared with the control (see figure 4). As a result of the reduction in the level of catalase activity in the brain of the treated animals this could lead to an increase in oxidative stress as reported by Brioukhanov et al. (2006). Increase in the free radicals in the brain has been reported to result in the decrease in density of 
dopaminergic receptors in the brain (Tiago et al., 2004) and this will result in having more dopamine in the system for longer period of time which in turn results in hyper-excitation, cell death, glial activation, and gliosis (Björklund and Dunnett, 2007).

\section{Neurobehaviour}

MDMA is a psychoactive drug that acts on the different neurotransmitters (dopamine and serotonin) to have it effect. It is shown that MDMA induces serotonin syndrome in rodent (Isbister et al., 2007). Most users of MDMA abuse it with other drugs. A symptom of serotonin syndrome in the rodent is a jerky movement of the limbs this has been attributed to excess serotonin and dopamine at the synapse (Ener et al., 2003). This study shows that animals treated with MDMA had lower motor function compared with the control (Fig. 2 and 3). Other studies have reported the similar observation that MDMA affect motor coordination and memory function (Callaghan et al., 2006; Li et al., 2006; Capela et al., 2009). Altered motor coordination may be due to the effect of the serotonin syndrome as the animal may not be able to balance well on the rotarod bar, although animal given the higher dose (20 $\mathrm{mg} / \mathrm{kg}, \mathrm{s.c}$ ) still perform more than the lower dose (10 mg/kg, s.c). The explanation for this looks tricky but epigenetic modification of the receptors at a higher dose may be a cause. It has been reported that alcohol which is another psychoactive agent has a different effect on dopamine release at acute and chronic state (Boileau et al., 2003). In this study, it was observed that the total locomotive activity of animals treated with $10 \mathrm{mg} / \mathrm{kg}$ of MDMA was significantly $(P<0.05)$ lower than the control group. No significant difference was observed between the control group and the high dose treated animals ( $p>0.05)$.

\section{Neurohistology}

The cerebellum plays an important role in motor function. Muscular input through mossy fibers project to the cerebellum, synapsing of the granular cells which later project to the Purkinje cells (Loewenstein et al., 2005). Purkinje neurons are the inhibitory neurons in the cerebellum which helps in modulating the cerebellum firing. This finding shows that animals given $10 \mathrm{mg} / \mathrm{kg}$ (s.c) of MDMA have more compacted granular cell layer than the control and the high dose $(20 \mathrm{mg} / \mathrm{kg}, \mathrm{s.c}$ ) (see fig. 13). Most input into the cerebellum enters into the granular cell layer to make a synapse before later relating to the Purkinje cells for modulation. Observations of the Purkinje cells indicate that animals given $10 \mathrm{mg} / \mathrm{kg} B W$ of MDMA have distorted Purkinje cells than the control, the effect of high dose been higher as there are lesser Purkinje cells. Since Purkinje cell is the only inhibitory neuron in the cerebellum, fewer Purkinje cells will lead to lesser inhibition of cerebellar output (Yartsey et al., 2009). This correlate with the behavioral result as animals given MDMA has low motor coordination (fig. 2 and 3). Lesser Purkinje cells lead to disinhibition of the cerebellar output thereby increasing the crude motor movement (Loewenstein et al., 2005), this makes fine movement coordination impossible.

The Glial cells and fibers are more stained in the treated group with higher dose showing more stain (see fig.14). Increase in glial cells especial the microglia is a sign of inflammation (DissingOlesen et al., 2007). Since MDMA inhibit MAO activity leading to excess dopamine at the synapse (Efthimia et al., 1994). Astrocyte has been shown to have receptors for neurotransmitters and help in mopping up excess neurotransmitters from the synapse (Figley and Stroman, 2011) and thereby by the result in their activation if prolonged. This explains why more microglia are been generated to clear off dead neuron, in the same way, more the astrocyte is been generated take up the excess neurotransmitters at the synapse. This may be a reason for increase in the No. of cells/unit area in the treated animals when compared with the control (see fig.9)

Research has shown that the hippocampus and the cerebellum are connected polysynaptically 
(Yu et al., 1989). This connection has been attributed to the function of the place cells in the hippocampus, the place cells are responsible for familiarizing with previous locations and areas. Studies show that the place cell depends on cues from the cerebellum (Rochefort et al., 2011) and report of experience of patients with cerebellar lesion shows that they have cognitive deficit especial matching space with time (Schmahmann, 1998). The present work shows that more granular cells were seen in the treated group (see fig. 11), the hippocampal-cerebellar connection involves the projection from CA1 and CA3 to lobule VI of the cerebellar cortex (Yu et al., 1989). Although, the cerebellum have been hypothesized to involve in higher cognitive function (Timmann and Daum, 2007). This study shows that MDMA increases the cell count in all areas of the hippocampus (CA1, CA2, 3 and DG) (fig. 6 - 8). Adeniyi et al. (2015) show that low dose ( $2 \mathrm{mg} / \mathrm{kg}, \mathrm{s.c}$ ) of MDMA reduced cell count in all areas of the hippocampus after a short period of time. This is not consistent with the present result which shows that $10 \mathrm{mg} / \mathrm{kg}$ and $20 \mathrm{mg} / \mathrm{kg}$ of MDMA increase the cell count in all regions of the hippocampus for 21 days. Although memory test was not done in this study, Adeniyi et al. (2015), shows that MDMA did not affect spatial memory at the dose used.
We hypothesized that MDMA at $10 \mathrm{mg} / \mathrm{kg}$ and $20 \mathrm{mg} / \mathrm{kg}$ in mice may affect spatial memory since hippocampus spatial memory processing depends on cues from the cerebellum as reported (Tomlinson et al., 2014).

In conclusion, Administration of MDMA (in short term) have no significant effect on the gross morphology of the animal. MDMA causes the excess release of neurotransmitters at the synapse as well as alteration in some biochemical metabolite involve in the metabolism of these neurotransmitters. The motor activities of animals treated with MDMA are affected. MDMA affect the cytoarchitecture of the brain cerebellum and the hippocampus bringing above cell death in the cerebellum as well as the proliferation of more glial cells in the hippocampus. The effects of the MDMA are dose depended.

\section{Acknowledgment}

We are grateful to the Nigerian Drug Law Enforcement Agency (NDLEA) for giving us the MDMA crystal. Also, we acknowledge Mr. Olawale Oso of the Department of Chemical Sciences, Afe Babalola University who worked with us in the preparation reagents.

\section{REFERENCES}

1. Adeniyi PA. 2010. Comparative effects of smoke and ethanolic extract of Tobacco (Nicotiana tabacum) leaves exposure on the frontal cortex and hippocampus of adult mice - Rhabdomys pumpilio M.Sc. Research Thesis, Department of Anatomy, University of Ilorin, Ilorin, Nigeria.

2. Adeniyi PA, Ishola AO, Laoye BJ, Olatunji BP, Bankole OO, Shallie PD, Ogundele OM. 2016. Neural and behavioral changes in male periadolescent mice after prolonged nicotine-MDMA treatment. Metab Brain Dis, 31 (1); 93-107.

3. Adeniyi PA, Olatunji BP. 2015. Biomedical research methods: The tool for all classes of research, Commissioner print, Akure, Nigeria, pg. 68.

4. Ajonijebu DC, Adeniyi PA, Adeleye AO, Olatunji BP, Ishola AO, Ogundele OM. 2014. "NicotineCadmium interaction alter exploratory motor function and increased anxiety in adult male mice," Journal of Neurodegenerative Disease. Article ID 359436, 9 pages.

5. Bankson MG, Cunningham KA. 2001. 3,4-Methylenedioxymethamphetamine (MDMA) as a unique model of serotonin receptor function and serotonin-dopamine interactions. J Pharmacol Exp Ther. 297(3):846-52.

6. Baron JA. 1986. Cigarette smoking and Parkinson's disease. Neurol. 36: 1490-1496. 
Anatomy Journal of Africa. 2017. Vol 6 (1): 884 -895

7. Björklund A, Dunnett SB. 2007. Dopamine neuron systems in the brain: an update. Trends Neurosci. 30 (5): 194-202.

8. Boileau I, Assaad JM, Pihl RO, Benkelfat C, Leyton M, Diksic M, Tremblay RE, Dagher A. 2003. Alcohol promotes dopamine release in the human nucleus accumbens. Synapse. 49(4):226-31.

9. Brioukhanov AL, Netrusov AI, Eggen RI. 2006. The catalase and superoxide dismutase genes are transcriptionally up-regulated upon oxidative stress in the strictly anaerobic archaeon Methanosarcina barkeri. Microbiology (Reading, Engl.). 152 (Pt 6): 1671-1677.

10. Callaghan PD, Owens WA, Javors MA, Sanchez TA, Jones DJ, Irvine RJ, Daws LC. 2006. In vivo analysis of serotonin clearance in rat hippocampus reveals that repeated administration of $p$ methoxyamphetamine (PMA), but not 3,4-methylenedioxymethamphetamine (MDMA), leads to longlasting deficits in serotonin transporter function. J Neurochem. 100(3):617-627.

11. Capela JP, Carmo H, Remião F, BastosML,Meisel A, Carvalho F. 2009. Molecular and cellular mechanisms of ecstasy-induced neurotoxicity: an overview. Mol Neurobiol. 39(3):210-271

12. Chelikani P, Fita I, Loewen PC. 2004. Diversity of structures and properties among catalases. Cellular and Molecular Life Sciences. 61 (2): 192-208.

13. Conte D, Narindrasorasak S, Sarkar B. 1996. In vivo and in-vitro iron-replaced zinc finger generates free radicals and causes DNA damage. The Journal Of Biological Chemistry. 271(9) 5125-30.

14. Deacon RMJ. 2013. Measuring Motor Coordination in Mice. J. Vis. Exp. (75), e2609

15. Del Río LA, Sandalio LM, Palma JM, Bueno P, Corpas FJ. 1992. Metabolism of oxygen radicals in peroxisomes and cellular implications. Free Radical Biology \& Medicine. 13 (5): 557-80.

16. Dissing-Olesen L, Ladeby L, Nielsen HH, Toft-Hansen H, Dalmau I, Finsen B. 2007. Axonal lesioninduced microglial proliferation and microglial cluster formation in the mouse. Neuroscience. $149(1): 122$.

17. Edmondson DE, Mattevi A, Binda C, Li M, Hubalek F. 2004. Structure and mechanism of monoamine oxidase. Curr. Med. Chem. 11(15): 1983-93.

18. Efthimia T, Leonardi M, Efrain C. 1994. MDMA (ecstasy)inhibition of Mao type A and type B: comparisons with fenfluramine and fluoxetine (Prozac). Neuropsychopharmacology, vol. 10, No 4.

19. EMCDDA. 2007. Annual report 2007: the state of the drugs problem in Europe. European Monitoring Centre for Drugs and Drug Addiction, Lisbon.

20. Ener RA, Meglathery SB, Van Decker WA, Gallagher RM. 2003. Serotonin syndrome and other serotonergic disorders. Pain Med. 4 (1): 63-74.

21. Figley CR, Stroman PW. 2011. The role(s) of astrocytes and astrocyte activity in neurometabolism, neurovascular coupling, and the production of functional neuroimaging signals". European Journal of Neuroscience. 33 (4): 577-588.

22. Franklin KBJ, Paxinos G. 2007. The mouse brain: in stereotaxic coordinates, Elsevier Oxford. 60.

23. Going JJ. 1994. Efficiently estimated histologic cell counts. Hum Pathol. 25(4):333-336

24. Hiner AN, Raven EL, Thorneley RN, García-Cánovas F, Rodríguez-López JN. 2002. Mechanisms of compound I formation in heme peroxidases. Journal of Inorganic Biochemistry. 91 (1): 27-34.

25. Isbister G, Bowe S, Dawson A, Whyte I. 2007. Relative toxicity of selective serotonin reuptake inhibitors (SSRIs) in overdose. J Toxicol Clin Toxicol. 42 (3): 277-85.

26. Johnston LD, O'Malley PM, Bachman JG, Schulenberg JE. 2008. Monitoring the future national survey results on drug use, 1975-2007, vol I: secondary school students. National Institute on Drug Abuse, Bethesda, MD

27. Li SX, Li J, Wang X, Peng ZG, Kuang WH, Huang MS. 2006. Long-term neurotoxic effects of MDMA result in cortical and hippocampal structural changes. Sheng Li XueBao. 58(1):34- 40. Chinese.

28. Loewenstein Y, Mahon S, Chadderton P, Kitamura K, Sompolinsky H, Yarom Y et al. 2005. Bistability of cerebellar Purkinje cells modulated by sensory stimulation. Nature Neuroscience. 8: 202-211. 
29. Meyer JS. 2013. 3,4-methylenedioxymethamphetamine (MDMA): current perspectives, Subst Abuse Rehabil 4:83-99.

30. Morgan MJ. 2000. Ecstasy (MDMA): a review of its possible persistent psychological effects. Psychopharmacology. 152:230-248.

31. Orchin M, Macomber RS, Pinhas A, Wilson RM. 2005. The Vocabulary and Concepts of Organic Chemistry. 2 ed: John Wiley \& Sons.

32. Parrott AC. 2001. Human psychopharmacology of Ecstasy (MDMA): a review of 15 years of empirical research. Human Psychopharmacol Clin Exp. 16:557-577.

33. Perrine JW, Takesue EI. 1968. Use of the rotarod in determining grip strength in rats with adjuvantinduced arthritis. Arch Int Pharmacodyn Ther. 174(1):192-8

34. Rochefort C, Arabo A, André M, Poucet B, Save E, Rondi-Reig L. 2011. Cerebellum shapes hippocampal spatial code. Science. 21;334(6054):385-9. doi: 10.1126/science.1207403.

35. Schmahmann JD. 1998. Dysmetria of thought: clinical consequences of cerebellar dysfunction on cognition and affect. Volume 2, Issue 9, Pages 362-371.

36. Tiago M. A, Emaneul V, Catarina R. O, Rodrigo A. C. 2004. Effect of free radicals on Adenosine $A_{2 A}$ and dopamine $D_{2}$ receptors in the striatum of young adult and aged rats. Neurochemistry international. 45: 733-738

37. Timmann D, Daum I. 2007. Cerebellar contributions to cognitive functions: a progress report after two decades of research. Cerebellum. 6(3):159-62.

38. Tipton KF, Boyce S, O'Sullivan J, Davey GP, Healy J. 2004. Monoamine oxidase; certainties and uncertainties. Curr. Med. Chem. 11(15): 1965-82.

39. Tomlinson SP, Davis NJ, Morgan HM, Bracewell RM. 2014. Cerebellar contributions to spatial memory. Neurosci Lett. 578:182-6.

40. UNODC. 2007. World drug report. United Nations Office on Drugs and Crime, Vienna.

41. Yartsev MM, Givon-Mayo R, Maller M, Donchin O. 2009. Pausing Purkinje cells in the cerebellum of the awake cat. Frontiers in Systems Neuroscience. 3: 2.

42. Yu QX, Gao JF, Wang JJ, Chen J. 1989. Hippocampus-cerebellar cortex-cerebellar nuclei projection in the rat: electrophysiological and HRP studies. Sheng Li Xue Bao. 41(3):231-40.

43. Zámocký M, Koller F. 1999. Understanding the structure and function of catalases: clues from molecular evolution and in vitro mutagenesis. Progress in Biophysics and Molecular Biology. 72(1):1966. 